\title{
VISOKOŠKOLSKE BIBLIOTEKE U SISTEMU NAUČNE KOMUNIKACIJE
}

\author{
Džejla Khattab* \\ dzejla.khattab@ff.unsa.ba \\ Lejla Hajdarpašić* \\ lejla.hajdarpasic@ff.unsa.ba \\ * Odsjek za komparativnu književnost i bibliotekarstvo, Katedra za bibliotekarstvo, Filozofski fakultet Univerziteta u \\ Sarajevu, Sarajevo, Bosna i Hercegovina \\ Department of Comparative Literature and Library Sciences, Department of Library Sciences, Faculty of Philosophy, \\ University of Sarajevo, Sarajevo, Bosnia and Herzegovina
}

\begin{abstract}
Sažetak
Prikupljanje, obrada, pohrana, očuvanje i diseminiranje produkata naučnog rada akademskog osoblja od esencijalnog su značaja za izgradnju prestiža jednog univerziteta, a imajući na umu da se naučne publikacije oduvijek koriste i kao sredstvo vrednovanja rada naučnih radnika, u ovom se radu argumentira potreba uključivanja visokoškolskih biblioteka u realizaciju različitih programa univerzitetskog izdavaštva orijentiranih ka promociji, tj. povećanju vidljivosti rezultata znanstvenih istraživanja akademske zajednice na međunarodnom nivou. lako bibliotekari u visokoškolskim bibliotekama raspolažu iskustvom kolaboracije u različitim programima izdavaštva, poput programa publiciranja e-časopisa, zbornika radova sa konferencija ili tehničkih izvještaja, u radu će se istaknuti potreba usavršavanja i usvajanja novih uloga za potrebe sazrijevanja i profesionalizacije ove sve prisutnije djelatnosti. S tim u vezi, ovaj rad tematizira važnu ulogu visokoškolskih biblioteka u izdavačkim programima univerziteta, izdvajajući dva osnovna načina na koji biblioteke daju svoj doprinos ovim procesima: kao izdavači i kao podrška izdavačkoj djelatnosti univerziteta. Rad problematizira u bosanskohercegovačkoj naučnoj i stručnoj literaturi iz bibliotečko-informacijskih nauka nedostajuće diskusije o prednostima uključivanja visokoškolskih biblioteka u izradu strategija unapređenja izdavačke djelatnosti univerziteta, odnosno uspostavljanja efikasnog sistema upravljanja naukom i inovacijama te poticanja izvrsnosti i relevantnosti naučnih istraživanja. Oslanjajući se na iskustvo akademskih biblioteka u korištenju i diseminiranju naučnih informacija unutar sistema naučne komunikacije, u radu se donosi zaključak da efikasno pozicioniranje akademske biblioteke u izdavaštvu naučnih informacija može proširiti i diverzificirati izdavačku djelatnost univerziteta, posebno u kontekstu inicijativa otvorenog pristupa (OA, engl. open access) te principa otvorene nauke (OS, engl. open science).
\end{abstract}

Ključne riječi: visokoškolske biblioteke, naučna komunikacija, otvoreni pristup, otvorena nauka

\section{Uvod}

Stoljećima su biblioteke i akademski izdavači partneri unutar istog sistema naučne komunikacije. Biblioteke su učestvovale u diseminaciji rezultata originalnih naučnih istraživanja tako što su stimulirale naučnu produkciju izgradnjom i očuvanjem bibliotečkih zbirki, kao što su učestvovale i u upravljanju različitim oblicima diseminacije naučnih informacija u formi naučnih časopisa i monografija te izgradnji institucionalnih repozitorija digitalnog doba. Uredi za univerzitetsko izdavaštvo osnivani u kampusima funkcionirali su kao podrška produkciji znanja uposlenika univerziteta, gdje su biblioteke, između ostalog, jačale zbirke razmjenom vlastitih izdanja s izdanjima drugih univerziteta. "Etos akademske zajednice istraživača je historijski uvijek bio nekomercijalan, te je diseminacija znanja historijski bila omogućena velikodušnošću organizacija koje se bave izdavaštvom - kao što su akademska udruženja i univerzitetski izdavači, sa misijom akademskog rada, a ne isključivo profita" (Fyfe et al. $2017,5)$. Transformacija izdavaštva i pitanja akademskog prestiža nakon Drugog svjetskog rata realizira se kroz jačanje i profesionalizaciju univerziteta u Evropi i Sjevernoj Americi, internacionalizaciju naučnih istraživanja te ekspanziju i "krizu" akademskog izdavaštva (Fyfe et al. 2017, 7-8). Omasovljenje visokog obrazovanja sa sobom će donijeti izazove zahtjeva studentske populacije su- 
očene sa visokim troškovima obrazovanja, zajedno sa pritiskom vlada koje očekuju povrat investiranih sredstava u menadžerski zahtjevnom okruženju sa povećanim brojem zaposlenih. "Mnogi univerziteti se sada mogu posmatrati kao velike korporacije, koje se sve više tako i ponašaju, sa liderima univerziteta koji usvajaju menadžerske tehnike iz drugih poslovnih modela" (Deem, Hillyard i Reed 2007).

Kao posljedica profesionalizacije visokog obrazovanja i internacionalizacije naučnog rada, broj publiciranih naučnih informacija doživljava ekspanziju i daljnji trend eksponencijalnog rasta te akademsko izdavaštvo postaje izuzetno komercijalno. Od 1980-ih akademsko izdavaštvo, koje je "ključno za sistem prepoznavanja reputacije i ima široko rasprostranjenu upotrebu kao oblik simboličnog kapitala unutar zajednice akademskih radnika i njenih institucija" (Blackmore 2016; Blackmore i Kandiko 2011), ulazi u "krizu serijskih publikacija" (engl. serials crisis), što je općeprihvaćeni termin za trend povećanja cijena naučnih informacija koje publiciraju univerzitetski izdavači.

Kao rezultat komercijalizacije univerzitetskih izdavača, akademsko priznavanje i reputacija koje su se historijski temeljile na ekspertizi zajednica profesionalaca, “...od 1960-ih i 1970-ih se usvajaju kod komercijalnih izdavača, što znači da su sada prodane kao ključna usluga dodane vrijednosti koja postoji unutar akademske zajednice" (Fyfe et al. 2017, 3). Veliki komercijalni izdavači su jako rano usvojili univerzitetsko izdavaštvo dostupno na internetu te su i dalje lideri u tom polju. S druge strane, pojava interneta za akademske radnike znači početak ere brže komunikacije sa drugim naučnicima iz međunarodne zajednice, ali i “...prešutno prihvaćanje transfera u online svijet postojećih struktura, radi alokacije profesionalne reputacije, a time i komercijalno orijentiranog modela izdavaštva" (Fyfe et al. 2017, 4). Troškovi papira, tinte, uveza i distribucije zamijenjeni su troškovima održavanja digitalne platforme za bržu globalnu diseminaciju naučnih izvora koja raspolaže kapacitetima za cirkulaciju znanja. Prikupljanje, obrada, pohrana, očuvanje i diseminiranje produkata naučnog rada akademskog osoblja od esencijalnog su značaja za izgradnju prestiža jednog univerziteta, a imajući na umu da se naučne publikacije oduvijek koriste i kao sredstvo vrednovanja rada naučnih radnika, ovaj će rad istaknuti ne samo potrebu kolaboracije visokoškolskih biblioteka sa partnerima iz ekosistema naučne komunikacije već i potrebu njihovog pozicioniranja u strategijama izgradnje reputacije institucije i njene međunarodne prepoznatljivosti. S tim u vezi, ovaj rad tematizira važnu ulogu visokoškolskih biblioteka u izdavačkim programima univerziteta, izdvajajući dva osnovna načina na koji biblioteke daju svoj doprinos ovim procesima: kao izdavači i kao podrš- ka izdavačkoj djelatnosti univerziteta, te ukazuje na prednosti uključivanja visokoškolskih biblioteka u izradu strategija unapređenja izdavačke djelatnosti univerziteta.

\section{Afirmacija visokoškolskih biblioteka u programima univerzitetskog izdavaštva}

Mogućnosti digitalne tehnologije i umrežene komunikacije, kao i cijena naučnih informacija, ubrzali su istraživanje alternativnih načina naučnog publiciranja. Na međunarodnom planu "visokoškolske biblioteke i njihove ustanove značajno su investirali $\mathrm{u}$ digitalne repozitorije i promociju modela otvorene nauke, što posljedično nastavlja da utječe na odlučnost fakulteta kroz rezolucije otvorenog pristupa i politike kampusa" (Mullins et al. 2012, 1). "Ovi rani napori su se pojavili u vrijeme razvoja komercijalnog softvera otvorenog koda koji podržava izdavanje i distribuciju naučnog rada" (Bonn i Furlough 2015,6 ), što će bibliotekama sa nedostatkom kapaciteta omogućiti eksperimentiranje s alternativnim načinima i modelima akademskog izdavaštva. Posljednih desetljeća investira se u realizaciju niza izvještaja o praksama izdavaštva u bibliotekama. Za dublje razumijevanje uloge visokoškolskih biblioteka kao izdavača naučnih informacija, krajem 2007. godine Američko udruženje istraživačkih biblioteka (ARL, Association of Research Libraries) utvrdilo je status aktivnosti svojih članica u pogledu eksperimentiranja s uslugama izdavaštva. Analiza je utvrdila da od 80 biblioteka članica Udruženja, njih $44 \%$ bilježi izdavačke aktivnosti, dok $21 \%$ planira razvoj takvih usluga (Hahn 2008, 5). Nadalje su L. Brown, bivša predsjednica Oxford University Pressa u SAD, i ITHAKA ${ }^{1}$ inicirali sponzoriranje i priređivanje izvještaja o univerzitetskom izdavaštvu prilagođenog digitalnom dobu (Brown, Griffiths i Rascoff 2007). Hahn $(2008,23)$ pozicionira bibliotečko izdavaštvo u prostor između tradicionalnih formi i novih modela izdavaštva, prepoznajući fokusiranje izdavaštva u bibliotekama na akademske proizvode visoke vrijednosti koji su izazvani usklađivanjem sa tržišnim zahtjevima komercijalnih izdavača. Nadalje slijedi istraživanje započeto 2010. godine u bibliotekama Univerziteta Purdue, Tehnološkog instituta Georgia i Univerziteta Utah koje su do tada imale komplementarno iskustvo i ekspertizu u izdavaštvu - "Purdue" publicirajući časopise u otvorenom pristupu, "Georgia" zbornike sa konferencija te "Utah" publicirajući monografije. U zaključku ovog izvještaja koji inicira Institut za muzejske i bibliotečke usluge (IMLS, Institute for Museum and

\footnotetext{
ITHAKA je neprofitna organizacija koja sarađuje sa globalnom akademskom zajednicom radi unapređivanja i očuvanja znanja te radi poboljšavanja učenja i podučavanja upotrebom digitalnih tehnologija.
} 
Library Services), naglašava se da ce inicijative izdavaštva u bibliotekama poslužiti kao katalizator razvoja i profesionalizacije djelatnosti (Mullins et al. 2012, 3). Oko trećina identificiranih programa publikuje tri do šest časopisa koji se isključivo distribuiraju elektronski i mlađi su od tri godine. Oko trećina programa publikuje zbornike radova sa konferencija, tehničke izvještaje ili monografije; najčešće elektronski, ali sa pojedinim primjerima distribucije štampanog formata na zahtjev. Usluge u vezi s izdavaštvom uključuju i savjetovanje u vezi $\mathrm{s}$ autorskim pravima, usluge digitalizacije i upravljanje procesom recenzije (Mullins et al. 2012, 6). Približno polovina analiziranih visokoškolskih biblioteka je za usluge izdavaštva, u saradnji sa jednom ili više institucija unutar kampusa, razvilo urede univerzitetskog izdavaštva ili informacijske centre, dok dvije trećine sarađuje sa pojedinicima i organizacijama izvan kampusa, a najčešće korištene platforme za publiciranje časopisa su Open Journal Systems (57\%), DSpace (36\%) i BePressov Digital Commons (25\%) (Mullins et al. 2012, 7).

Identificiranje uspješnih bibliotečkih strategija i usluga $u$ vezi s izdavaštvom te sagledavanje prioriteta u vezi s izgradnjom kapaciteta za saradnju unutar kampusa artikulirali su prioritete za planiranje/ upravljanje modelom izdavaštva unutar biblioteka. Dok visokoškolske biblioteke nastavljaju usluživati korisnike dosadašnjim ulogama koje su od interesa za izdavaštvo, kao što su kreiranje metapodataka i indeksiranje, očuvanje, usluge koje uključuju tehnologiju - "discovery service" kao poboljšana usluga pretraživanja, digitalne biblioteke i usluge repozitorija, gore spomenuti izvještaji, nastali kao sinteza prikupljenih podataka i iskustava, uključuju organizacijske aspekte izdavačkih programa, kao i ekonomske razloge saradnje u novim digitalnim okruženjima, najčešće akcentirajući strategiju otvorenog pristupa, te sugeriraju značaj istraživanja izdavaštva u bibliotekama, što je u skladu sa misijom visokoškolske biblioteke digitalnog doba koja je uključena u procese kreiranja i publiciranja znanja.

Uključivanje bibliotekara u radne procese izdavaštva opravdava širok spektar vještina bibliotekara u organizaciji znanja. Tradicionalne vještine bibliotekara itekako su relevantne za izdavaštvo digitalnog doba te s tim u vezi McCormick $(2015,64)$ izdvaja niz vještina koje mogu funkcionirati kao podrška programima izdavaštva: selekcija i izgradnja zbirki, upravljanje i konverzija strukturiranih metapodataka, implementacija tehničkih standarda kao preduvjeta pretraživosti, menadžment hardvera i softvera, označavanje teksta i kodiranje, digitalno očuvanje kao preduvjet dugoročnog pristupa digitalno rođenim materijalima, razvoj softvera i vještine programiranja, razvoj repozitorija s ciljem hostinga sadržaja te iskustvo u kreiranju i osiguravanju pristupa digitalnim zbirkama putem weba. Walters (2012, 443-444) navodi novije vještine koje su neophodne za uspjeh samostalnih izdavačkih programa u bibliotekama: stvaranje poslovnih modela i prihoda, marketing, upravljanje projektima, autorska prava, ekspertiza u tehnologijama izdavačke djelatnosti, uključujući razvoj softvera, programiranje i web dizajn, uspostavljanje usluge izdavaštva te vještine opservacije ponašanja akademskih radnika i fakulteta unutar različitih disciplina. Na putu ka sazrijevanju unutar ove relativno nove i rastuće grane izdavaštva, bibliotekari mogu koristiti vještine manje formalnih modela publiciranja, primjerice zbornika radova sa konferencija. U ovim manje zahtjevnim programima, bibliotekari mogu zagovarati sponzorstvo akademskih udruženja i univerzitetskih izdavača kao partnera koji podržavaju bibliotečke programe publiciranja, što će povećati legitimitet biblioteka u ovom polju ekspertize. Ipak, s tim u vezi treba naglasiti da su pojedina istraživanja pokazala da postojeći programi obrazovanja bibliotekara nedovoljno pripremaju stručnjake za teoretska, praktična i organizacijska pitanja izdavaštva pa je, s ciljem jačanja kompetencija bibliotekara u ovoj oblasti te njihove dodatne afirmacije u budućim programima izdavaštva, neophodno kontinuirano revidirati programe obrazovanja (Skinner et al. 2014).

Studija slučaja ureda za izdavaštvo Nacionalnog univerziteta Australije (ANU, Australian National University) predstavlja primjer uspješnog usvajanja modela otvorenog izdavaštva smještenog u biblioteci, unatoč kontroverzama koje nastaju kao odgovor na lociranje ureda za univerzitetsko izdavaštvo unutar biblioteka (Missingham i Kanellopoulos 2014). U šest univerziteta u Australiji postoji uska saradnja između biblioteka i izdavača, što je iniciralo formiranje udruženja univerzitetskih izdavača univerziteta u Australiji (Australian Univesities Publishers Group) (Missingham and Kannelopoulos 2013).

Prateći povećanje broja zabilježenih praksi kolaboracije između biblioteka i univerzitetskih izdavača, Watkinson (2015, 86-91) donosi taksonomiju različitih relacija koje se uspostavljaju između organizacija unutar različitih modela izdavaštva, pri čemu ističe one za koje postoji najviše dokaza kroz zajedničke projekte, gdje organizacije zadržavaju potpunu ili relativnu autonomiju, sa kolokacijom osoblja i kapaciteta ili bez nje. Česti su modeli izdavaštva koji se realiziraju u sinergiji univerziteta, visokoškolskih biblioteka univerziteta i ureda za univerzitetsko izdavaštvo i/ili akademskih udruženja, a koji biblioteku pozicioniraju kao kompetitivnog izdavača. Dok pojedini univerziteti imaju uspješne modele zasebnih ureda za izdavaštvo poput Oxforda ili Cambridgea i raspolažu kapitalom od nekoliko desetljeća i više, Walters $(2012,447)$ ističe da biblioteke kompetitivnost postižu smanjivanjem troškova 
za krajnjeg korisnika, raspolažući pritom prihodima za opravdavanje vlastitih troškova, kao i ulaganjem finansijskog viška u daljnji razvoj ovog modela. Ovakav model olakšava univerzitetu provođenje misije diseminiranja znanja, na koje zadržava autorska prava, uz fleksibilnost u eksperimentiranju sa novim modelima diseminacije znanja, pri tome kontrolirajući troškove. Budući da neće sve akademske discipline na isti način vrednovati bibliotečko izdavaštvo, Walters $(2012,449)$ analizira model biblioteke kao specijaliziranog izdavača $i$ ističe prednosti za izgradnju reputacije univerziteta kroz publiciranje naučnih informacija iz ključnih polja ekspertize. Usprkos predviđanjima da će pojedini izdavači nastaviti dominaciju u određenim poljima ekspertize te unatoč relativno malom kapacitetu i zavisnosti od finansiranja matične ustanove, biblioteke mogu razmotriti netradicionalne forme i neformalne pristupe naučnom izdavaštvu u digitalnom okruženju (usp. Walters 2012, 449-451). Iako u digitalnom dobu saradnja visokoškolskih biblioteka i univerzitetskih izdavača, kao učesnika istog ekosistema naučne komunikacije, ne bi trebala izostajati, donedavno nije bilo zabilježenih uspješnih primjera uske saradnje u publikovanju znanja. Uz brojne dokumentovane modele kolaboracije biblioteka u izdavaštvu naučnih informacija, neizostavna je i uloga koju mogu ostvariti kao konsultanti u procesima izdavaštva (Walters 2012, 452). Iako limitirana, ova uloga podrazumijeva fokusiranje na pitanja $u$ vezi s autorskim pravima te promociju otvorenog pristupa u diseminiranju naučnih informacija. U tom smislu je neprijeporno važna i izgradnja institucionalnih repozitorija univerziteta, koji predstavljaju skup servisa koje univerzitet nudi članovima svoje zajednice i koji su namijenjeni upravljanju i distribuciji digitalne građe proizvedene u instituciji ili od strane članova zajednice (Lynch, 2013). Institucionalni repozitoriji otvorenog pristupa način su za ostvarivanje esencijalnog cilja zajednice okupljene oko otvorenog pristupa, a taj je povećati dostupnost rezultata znanstvenih istraživanja u sistemu umrežene komunikacije.

Naprijed izdvojeni primjeri izdavačkih aktivnosti biblioteka govore u prilog tome da se u ovoj domeni biblioteke pojavljuju kao formalni izdavači i/ili pak kao servis, podrška univerzitetskom izdavaštvu. Potonji model, u kojem je akademsko osoblje zaduženo za uredničku politiku, a u kojem biblioteke daju produkcijsku i distribucijsku podršku (Bonn i Furlough 2015, 7), naglašeno je dominantan u univerzitetskim izdavačkim programima, pogotovo onim koji slijede principe otvorenog pristupa. Ipak, takvi trendovi ne bi trebali biti prepreka uspostavljanju modela izdavaštva u kojima biblioteke preuzimaju ulogu izdavača u cijelosti.

\section{Inicijativa otvorenog pristupa i principi otvorene nauke}

Učešće biblioteka u univerzitetskim izdavačkim projektima ponajviše je orijentirano u pravcu promovisanja i njegovanja koncepta otvorenog pristupa naučnim informacijama. Inicijativa otvorenog pristupa (OA, engl. open access) nastala je kao odgovor na visoke cijene naučnih informacija, odnosno tržišnu moć komercijalnih izdavača naučnih časopisa, a njeni principi temelje se na nekoliko deklaracija u setu kojih su najveću pažnju dobile Budimpeštanska inicijativa (2001) te Berlinska deklaracija o otvorenom pristupu znanju u nauci (2003). Budimpeštanska inicijativa definira otvoreni pristup naučnoj literaturi kao "slobodnu dostupnost na javnom internetu koja svakom korisniku omogućava čitanje, preuzimanje, kopiranje, distribuiranje, printanje, pretraživanje... bez finansijskih, pravnih ili tehničkih ograničenja". U pogledu prava intelektualnog vlasništva, Budimpeštanska inicijativa naglašava da se jedina obaveza zaštite intelektualnog vlasništva odnosi na integritet autora i njegova djela, odnosno na ispravno navođenje autora i djela ( $\mathrm{Bu}$ dapest Open Access Initiative, 2002). Za razliku od Budimpeštanske inicijative, Berlinska deklaracija o otvorenom pristupu navodi da doprinosi otvorenom pristupu uključuju izvorne rezultate naučnih istraživanja, ali i sirove podatke te metapodatke, izvorne podatke, slikovnu i grafičku građu u digitalnom obliku, naučnu multimedijalnu građu, pa u tom smislu Berlinska deklaracija ima za cilj promovirati internet kao instrument za izgradnju globalnog i interaktivnog prikaza ljudskog znanja te odrediti mjere koje istraživačke institucije, agencije koje finansiraju istraživanja, biblioteke, arhivi i muzeji trebaju razmotriti (Berlin Declaration on Open Access to Knowledge in the Sciences and Humanities, 2003).

Velika popularnost inicijative omogućavanja slobodne i neograničene pristupačnosti naučne literature, koju dokazuje podatak od čak 13,884 časopisa, iz 130 zemalja, arhiviranih u DOAJ direktoriju (DOAJ, novembar 2019. godine), omogućila je visokoškolskim bibliotekama da povećaju pristup sadržajima, jačajući tako svoje informacijske usluge, da aktivno zagovaraju i promoviraju koncept otvorenog pristupa, a važnije, s ciljem povećanja vidljivosti naučne produkcije univerziteta, da se uključe u izdavačke projekte ovoga tipa. Imajući na umu da se otvoreni pristup ostvaruje i putem arhiviranja i/ili samoarhiviranja u repozitorije ili arhive, visokoškolske biblioteke su dale svoj, ranije spomenuti, doprinos i u izradi i održavanju univerzitetskih institucionalnih arhiva ili repozitorija u otvorenom pristupu. Budući da ovakvi repozitoriji ne postavljaju ograničenja na pristup sadržajima, oni doprinose poboljšanju ugleda institucije, čineći njene rezultate istraživanja vidljivim i dostupnim te pružajući potencijalne ala- 
te za praćenje i procjenu istraživanja u institucijama (Study on economic and technical evolution of the scientific publication markets in Europe 2006, 61). Izgradnju takvih repozitorija omogućili su ponajviše programi poput Eprintsa te Dspacea, a treba s tim u vezi spomenuti da je razvoj ovih programa, brinući se o interoperabilosti sadržaja, pratila OAI inicijativa (Open Archives Initiative), koja je davne 2001. godine strukturirala OAI-PMH (Open Archives Initiative Protocol for Metadata Harvesting), protokol za pobiranje metapodataka.

Kao posljedica inicijative otvorenog pristupa, slobodnoj dostupnost rezultata istraživanja biblioteke doprinose učestvujući aktivno u njegovanju principa otvorene nauke. FOSTER definira otvorenu nauku kao pokret kojim se naučna istraživanja i podaci čine dostupnim svim nivoima društva (FOSTER, Open Science Definition), temeljeći se na principima povećane transparentnosti, ponovne upotrebljivosti, participaciji, saradnji, odgovornosti i obnovljivosti istraživanja. Cilj otvorene nauke jest poboljšati kvalitetu i pouzdanost istraživanja putem načela kao što su uključivanje, poštenje, pravednost i dijeljenje (Open Science Training Handbook 2018), a kojima upravo biblioteke doprinose na različite načine: zagovaranjem i podizanjem svijesti o otvorenoj nauci, pri čemu promoviranje prednosti otvorene nauke treba pratiti razvoj alata i usluga, mehanizama poticanja i prepoznavanja izvrsnosti u otvorenoj nauci; davanjem podrške infrastrukturi razmjene, članaka ili podataka, uključivanjem u razvoj i upravljanje repozitorijima, u pogledu procjene, odabira, opisa i primjene metapodataka, očuvanja, pohranjivanja i pretraživanja informacija te praćenja ponovne upotrebe podataka; davanjem doprinosa razvoju politika i strategija upravljanja podacima istraživanja; treniranjem i davanjem podrške istraživačima u upravljanju podacima, primjeni metapodataka, identifikaciji istraživačkih metoda $\mathrm{i}$ alata u otvorenom pristupu, citiranju podataka, licenciranju, pripremi podataka za deponovanje i dugoročno očuvanje i tome slično (FOSTER, Libraries: roles and opportunities on Open Science 2019). Izvještaj, odnosno analiza politika otvorene nauke u Evropi iz augusta 2019. godine, detektovao je da su u izradi takvih nacionalnih dokumenata o otvorenom pristupu i otvorenoj nauci u evropskom prostoru učestvovale i nacionalne biblioteke (An Analysis of Open Science Policies in Europe 2019, 32 , a valja s tim u vezi naglasiti i da nova direktiva EU o otvorenim podacima s posebnom pažnjom tematizira pristupačnost takvih sadržaja u kontekstu otvorenog pristupa i otvorene nauke, navodeći u članu 28. obavezu "država članica da usvoje politike otvorenog pristupa u odnosu na javno financirane istraživačke podatke i osiguraju da takve politike provode sve organizacije koje provode istraživanja"
(Directive on open data and the re-use of public sector information 2019).

Misiju univerzitetskih izdavača, kao i visokoškolskih biblioteka, koje nastaju kao derivati utemeljenja univerzitetskog obrazovanja, nije moguće posmatrati odvojeno od misije univerziteta kojem pripadaju. Univerziteti se moraju osloniti na pouzdane kanale diseminacije znanja, kao produkta nastavnog i naučnog rada akademske zajednice, ali i načine očuvanja i organizacije proizvedenog znanja, kao sastavnog dijela ekosistema naučne komunikacije. U tom smislu, pažljiv pristup problematici arhiviranja, očuvanja te diseminacije naučnih informacija zagovaraju i Preporuke Evropske komisije o pristupu naučnim informacijama i njihovom očuvanju iz 2018. godine koje, podsjećajući na činjenice da je to "tradicionalna" odgovornost biblioteka ili arhiva, da je očuvanje rezultata naučnih istraživanja od javnog interesa te da su rezultati naučnih istraživanja u stalnom porastu, navode da se moraju kreirati mehanizmi, infrastrukture i softverska rješenja koja će omogućiti očuvanje rezultata istraživanja koji se pojavljuju u digitalnom obliku (Commission Recommendation (EU) on access to and preservation of scientific information 2018).

\section{Zaključna razmatranja}

Kao odgovor na porast broja izdavačkih aktivnosti u bibliotekama te kao mjesto susreta teoretičara i praktičara, ne iznenađuje što je 2013. godine osnovano i Udruženje bibliotečkog izdavaštva (Library Publishing Coalition) kao organizacija posvećena upravo jačanju izdavačkih aktivnosti biblioteka, odnosno podržavanju i produbljivanju interesa biblioteka u takvim aktivnostima (Library Publishing Coalition Strategic Plan 2018-2023, 2). Sve veće učešće biblioteka u različitim izdavačkim projektima ponukalo je i osnivanje IFLA-ine specijalne interesne grupe za izdavaštvo u bibliotekama (IFLA Library Publishing Special Interest Group), koja je februaru 2019. godine održala svoj prvi sastanak, kojom prilikom su prezentirani i obrazlagani različiti primjeri izdavačke djelatnosti biblioteka, tematizirane prednosti uspostavljanja međuinstitucionalne saradnje u ovoj domeni i tome slično. Iako tek nedavno formirana, može se očekivati da će u nadolazećem periodu ova grupa promovirati, zagovarati veće učešće biblioteka u izdavačkim projektima, donoseći različita istraživanja u ovoj oblasti, odnosno detektujući nadolazeće trendove u domeni naučnog izdavaštva. Postojeći pak primjeri dobre prakse govore u prilog tome da napori orijentirani u pravcu osmišljavanja odgovarajućih strategija razvoja izdavačke djelatnosti univerziteta trebaju uključiti reprezentativna iskustva visokoškolskih biblioteka u procesima komunikacije i diseminacije naučnih informacija. Tijesnom kontinuiranom 
saradnjom informacijskih stručnjaka, akademskog osoblja i menadžmenta, u procesu strukturiranja politika izdavačke djelatnosti prilagođenih savremenom okruženju, a ponajviše trendovima otvorenog pristupa i otvorene nauke, mogu se potpunije analizirati te isplanirati svi radni procesi univerzitetskog izdavaštva, a sve s ciljem povećanja vidljivosti i konkurentnosti naučne produkcije univerziteta.

\section{Literatura}

- An Analysis of Open Science Policies in Europe, v4. 2019. SPARC Europe, DCC. https://zenodo.org/record/3379705\#.XbxvqEVKjfZ. Datum pristupa: 5. 9. 2019 .

- Berlin Declaration on Open Access to Knowledge in the Sciences and Humanities, 2003. https://openaccess.mpg.de/67605/berlin_declaration_engl.pdf. Datum pristupa: 6. 9. 2019.

- $\quad$ Blackmore, P., i Kandiko, C. B. 2011. "Motivation in academic life: a prestige economy" Research in Post Compulsory Education 16(4): 399-411. doi: https:// doi.org/10.1080/13596748.2011.626971.

- Blackmore, P. 2016. Prestige in Academic Life: Excellence and Exclusion. Abingdon: Routledge.

- Bonn, M., i Furlough, M. 2015. Getting the world out: Academic libraries as scholarly publishers. Chicago: Association of College and Researh Libraries. http://www.ala.org/acrl/sites/ala.org.acrl/files/ content/publications/booksanddigitalresources/digital/9780838986981_getting_OA.pdf. Datum pristupa: 5. 6. 2019.

- Brown, Laura, Rebecca J. Griffiths, i Rascoff, Matthew. 2007. University Publishing in a Digital Age. New York: Ithaka. doi: https://doi.org/10.18665/ sr.22345.

- Budapest Open Access Initiative. 2002. https://www. budapestopenaccessinitiative.org/read. Datum pristupa: 6. 9. 2019.

- Commission Recommendation (EU) 2018/790 of 25 April 2018 on access to and preservation of scientific information, L 134/12. https://www.eosc-portal.eu/ sites/default/files/CELEX_32018H0790_EN_TXT. pdf. Datum pristupa: 31. 5. 2018.

- Deem, R., Hillyard, S., i Reed, M. 2007. Knowledge, Higher Education and the New Managerialism: the changing management of UK universities. Oxford University Press.

- Directive (EU) 2019/2024 of the European parliament and of the Council of 20 June 2019 on open data and the re-use of public sector information (recast), L 172/56, 26. 6. 2019. https://eur-lex.europa. eu/legal-content/EN/TXT/?qid=1561563110433\&u ri=CELEX:32019L1024 Datum pristupa: 5. 9. 2019.
- FOSTER. Libraries: roles and opportunities on Open Science. 2019. https://www.fosteropenscience. $\mathrm{eu} /$ content/libraries-roles-and-opportunities-openscience Datum pristupa: 10. 5. 2018.

- FOSTER, Open Science Definition. https://www. fosteropenscience.eu/foster-taxonomy/open-science-definition. Datum pristupa: 10. 5. 2018.

- $\quad$ Fyfe, A., Coate, K., Curry, S., Lawson, S., Moxham, N., i Rostvik, C. M. 2017. Untangling Academic Publishing: a history of the relationship between commercial interests, academic prestige and the circulation of research. doi: https://doi.org/10.5281/zenodo.

- Hahn, Karla. 2008. Research Library Publishing Services: New Options for University Publishing. Washington, DC: Association of Research Libraries. https://files.eric.ed.gov/fulltext/ED500889.pdf. Datum pristupa: 11. 6. 2019.

- Library Publishing Coalition Strategic Plan 20182023. Released August 2018. https://librarypublishing.org/wp-content/uploads/2018/08/LPC_StrategicPlan_August2018.pdf. Datum pristupa: 5. 9. 2019.

- Lynch, Clifford. 2003. "Institutional Repositories: Essential Infrastructure for Scholarship in the Digital Age." ARL Bimonthly Report 226, February. http://www.arl.org/newsltr/226/ir.html. Datum pristupa: 8. 8. 2019.

- McCormick, Monica. 2015. “Toward New-Model Scholarly Publishing: Uniting the Skills of Publishers and Libraries" U Bonn, M., i Furlough, M., ur. Getting the world out: Academic libraries as scholarly publishers. Chicago: Association of College and Researh Libraries. http://www.ala.org/acrl/sites/ ala.org.acrl/files/content/publications/booksanddigitalresources/digital/9780838986981_getting _ OA.pdf. Datum pristupa: 5. 6. 2019.

- Missingham, Roxanne, i Lorena Kannelopoulos. 2013. "A Decade of Running a University E-Press" U Library Publishing Toolkit, uredila Allison P. Brown. Geneseo, NY: IDS Project Press.

- Mullins, J. L., Murray-Rust, C., Ogburn, J. L., Crow, R., Ivins, O., Mower, A., Nesdill, D., Newton, M. P., Speer, J., i Watkinson, C. 2012. Library Publishing Services: Strategies for Success: Final Research Report. Washington, DC: SPARC. 
- $\quad$ Skinner, K., Lippincott, S., Speer, J., i Walters, T. 2014. "Library-as-Publisher: Capacity Building for the Library Publishing Subfield" Education and Training for 21st Century Publishers 17(2). doi: http:// dx.doi.org/10.3998/3336451.0017.207.

- Study on economic and technical evolution of the scientific publication markets in Europe. 2006. Final report, January 2006, Commisioned by DGResearch, European Commision. https://ec.europa. eu/research/openscience/pdf/openaccess/librarians_2006_scientific_pub_study.pdf. Datum pristupa: 5.9 .2019 .
- Walters, Tyler. 2012. "The Future Role of Publishing Services in University Libraries" Portal: Libraries and the Academy 12(4): 425-454. Project MUSE. doi:10.1353/pla.2012.0041.

\title{
ACADEMIC LIBRARIES IN THE SYSTEM OF SCIENTIFIC COMMUNICATION
}

\begin{abstract}
Collecting, processing, storing, preserving and disseminating scientific products of academic staff are essential for building the prestige of a university, especially bearing in mind that scientific publications have always been used as a means of evaluating the work of scientists. This paper argues for the need to involve academic libraries in the implementation of various university publishing programs oriented towards promotion or increasing the visibility of the results of academic research the international level. Although librarians in academic libraries have the experience of collaborating in various publishing programs, such as e-journal publishing programs, conference proceedings, or technical reports, this paper will focus on the need for improving and adopting new roles for the needs of maturing and professionalizing of this prevalent activity. In this regard, this paper focuses on the important role of academic libraries in university publishing programs, highlighting two basic ways in which libraries contribute to these processes, as publishers and in supporting university publishing, emphasizing the benefits of including academic libraries in developing university publishing strategies. This paper focuses on the lack of discussions in the B\&H scientific and professional literature about the importance of publishing in academic libraries, which from an economic point of view is indisputably important as a new source of funding on campus, which strengthens the financial independence of the university, especially in the period of establishing an effective science and innovation management strategy and encouraging excellence and relevance of scientific research. Drawing on the experience of academic libraries in the use and dissemination of scientific information within the scientific communication system, the paper concludes that effective positioning of the academic libraries in the publishing of scientific information can broaden and diversify the university's publishing activities, especially in the context of open access initiatives (OA) and open science principles (OS).
\end{abstract}

Keywords: academic libraries, scientific communication, open access, open science 